\title{
Habituation to a Deterrent Plant Alkaloid Develops Faster in the Specialist Herbivore Helicoverpa assulta Than in Its Generalist Congener Helicoverpa armigera and Coincides with Taste Neuron Desensitisation
}

\author{
Dong-Sheng Zhou ${ }^{1,2,3}$, Chen-Zhu Wang ${ }^{2, *}$ and Joop J. A. van Loon ${ }^{3, *}$ \\ 1 Hunan Key Laboratory for Conservation and Utilization of Biological Resources in the Nanyue Mountainous \\ Region, College of Life Sciences and Environment, Hengyang Normal University, Hengyang 421008, China; \\ zhouds@hynu.edu.cn \\ 2 State Key Laboratory of Integrated Management of Pest Insects and Rodents, Institute of Zoology, \\ Chinese Academy of Sciences, Beijing 100101, China \\ 3 Laboratory of Entomology, Wageningen University, 6700 AA Wageningen, The Netherlands \\ * Correspondence: czwang@ioz.ac.cn (C.-Z.W.); joop.vanloon@wur.nl (J.J.A.v.L.); \\ Tel.: +86-10-6480-7115 (C.-Z.W.); +31-317-482791 (J.J.A.v.L.)
}

Citation: Zhou, D.-S.; Wang, C.-Z.; van Loon, J.J.A. Habituation to a Deterrent Plant Alkaloid Develops Faster in the Specialist Herbivore Helicoverpa assulta Than in Its Generalist Congener Helicoverpa armigera and Coincides with Taste Neuron Desensitisation. Insects 2022, 13, 21. https://doi.org/10.3390/ insects13010021

Academic Editors: Sylvia Anton and Romina B. Barrozo

Received: 29 November 2021 Accepted: 22 December 2021 Published: 23 December 2021

Publisher's Note: MDPI stays neutral with regard to jurisdictional claims in published maps and institutional affiliations.

Copyright: (C) 2021 by the authors. Licensee MDPI, Basel, Switzerland. This article is an open access article distributed under the terms and conditions of the Creative Commons Attribution (CC BY) license (https:// creativecommons.org/licenses/by/ $4.0 /)$.
Simple Summary: Habituation to deterrent plant compounds has been found in generalist and specialist insect herbivores. The rate at which plant-feeding insects habituate and at which sensitivity of taste neurons detecting deterrents changes has not been compared among closely related species. The generalist Helicoverpa armigera (Hübner) and the specialist Helicoverpa assulta (Guenée) (Lepidoptera: Noctuidae) differ strongly in degree of host-plant specialism. Both species habituated to the alkaloid strychnine after dietary exposure; however, the specialist $H$. assulta displayed habituation to strychnine faster (at $48 \mathrm{~h}$ ) than the generalist H. armigera (at $72 \mathrm{~h}$ ). Electrophysiological recordings from taste sensilla on mouthparts revealed that a deterrent-sensitive neuron in the medial sensillum styloconicum of both species displayed significantly reduced sensitivity to the deterrent that coincided in time with the onset of habituation. Our findings show that physiological changes in taste neuron sensitivity coincide with habituation to plant compounds that are initially avoided.

Abstract: The two closely related moth species, Helicoverpa armigera and H. assulta differ strongly in their degree of host-plant specialism. In dual-choice leaf disk assays, caterpillars of the two species that had been reared on standard artificial diet were strongly deterred by the plant-derived alkaloid strychnine. However, caterpillars of both species reared on artificial diet containing strychnine from neonate to the 5th instar were insensitive to this compound. Fifth instar caterpillars of $H$. assulta and 4 th or 5 th instars of $H$. armigera not exposed to strychnine before were subjected to strychninecontaining diet for $24 \mathrm{~h}, 36 \mathrm{~h}, 48 \mathrm{~h}$, or $72 \mathrm{~h}$. Whereas $H$. assulta displayed habituation to strychnine after $48 \mathrm{~h}$, it took until $72 \mathrm{~h}$ for H. armigera to become habituated. Electrophysiological tests revealed that a deterrent-sensitive neuron in the medial sensillum styloconicum of both species displayed significantly reduced sensitivity to strychnine that correlated with the onset of habituation. We conclude that the specialist $H$. assulta habituated faster to strychnine than the generalist $H$. armigera and hypothesis that desensitization of deterrent-sensitive neurons contributed to habituation.

Keywords: habituation; taste desensitization; strychnine; Helicoverpa armigera; Helicoverpa assulta

\section{Introduction}

The taste system of insects plays an important role in detecting and assessing foodrelated chemicals. Plant-feeding insect species display remarkable differences in host-plant specialization. Some species feed on plants from many families and are named 'generalists', whereas the majority of species feed on plants belonging to a single plant family, genus and often only a single species and are called 'specialists'. The discrimination of food by insects 
depends primarily on neural input from their chemosensory systems. In lepidopteran larvae, host-plant discrimination is governed by information from taste neurons that are located primarily on the ventral side of the labrum, the maxillary palps and galea [1,2]. Taste neurons innervating the lateral and medial sensilla styloconica on the maxillary galea play a decisive role in food selection behavior. Former studies have classified the taste neurons in the two sensilla styloconica of several caterpillar species as sugar cell, water cell, salt cell, amino acid cell, inositol cell, deterrent cell, etc. [1]. All herbivorous insects are equipped with deterrent cells, the activation of which leads to an aversive behavioral response [1,3-6].

Many studies showed that food selection of herbivorous insects is not fixed and can be modified by dietary experiences [7-13]. It has been documented that a change in food selection behavior normally is associated with changes in taste neuron sensitivity [14-17]. Taste neuron sensitivity can change adaptively as a result of food experience [16]. Such changes can take two forms: (1) taste neuron sensitivity can be enhanced because the contacted compounds that serve as token stimuli, defined as recognition cues that have a specific botanical occurrence $[9,14,15,18]$; (2) in contrast, taste neurons may become less sensitive when they have been exposed to deterrent-containing food for a certain period of time [19-24]. For example, insects fed a standard artificial diet containing a low level of a feeding deterrent show desensitization of deterrent-sensitive taste neurons [1]. Such reduced sensory responsiveness has been reported in several studies [10-12,19-24]. Reduced taste neuron sensitivity as a result of dietary history has been reported for both generalist and specialist species [1] and for two phylogenetically closely related specialist species [25]. Here we compared two congeneric Helicoverpa species, a specialist and a generalist, focusing on the rate at which habituation and desensitisation develop.

Helicoverpa armigera (Hübner) and Helicoverpa assulta (Guenée) (Lepidoptera: Noctuidae) are closely related species which exhibit a clearly different degree of host-plant specialism. The former is a generalist feeding on plants from more than 40 families and the latter is a specialist using several species in the family Solanaceae as host plants, such as tobacco and hot pepper $[26,27]$. In this study, we report the behavior and electrophysiological responses of the two species after experiencing either a standard diet or a diet containing strychnine during varying exposure times. We addressed three questions: (1) Do the two species habituate to the same deterrent? (2) If so, is the rate of habituation similar? (3) Are the onset of habituation and desensitization coinciding?

\section{Materials and Methods}

\subsection{Insects}

Helicoverpa armigera and H. assulta were collected from fields in Henan Province, China. We collected the 4th-5th larvae (ca. 200 each time) in July-September every year and these were maintained in the laboratory for the rest of the year. Laboratory colonies of $H$. armigera and $H$. assulta were maintained as continuous cultures in the laboratory in an environmental chamber (about $10 \mathrm{~m}^{2}$ ) under a L16:D8 photo: scotoperiod, at a temperature of $25 \pm 1{ }^{\circ} \mathrm{C}$ and $\mathrm{RH} 60-70 \%$. Larvae were reared individually in glass tubes plugged with cotton wool on the standard artificial diet (see below). Adults (30 adults with 1:1 ratio of female to male) were kept in $40 \mathrm{~cm} \times 40 \mathrm{~cm} \times 40 \mathrm{~cm}$ wooden cages and supplied with a $10 \%$ solution of honey in water.

\subsection{Diets}

Two types of diets were used: the standard artificial rearing diet for H. armigera [28], prepared using the following ingredients (ca. $1 \mathrm{~kg})$ : wheat germ $(150 \mathrm{~g})$, yeast powder (30 g), methyl-p-hydroxybenzoate (2 g), sorbic acid (1 g); ascorbic acid ( $3 \mathrm{~g})$, linoleic acid $(1 \mathrm{~mL})$, agar $(14 \mathrm{~g})$, tomato paste $(198 \mathrm{~g})$, and distilled water $(600 \mathrm{~mL})$. The rearing diet for $H$. assulta was the same as that of $H$. armigera diet except that chili powder $(8 \mathrm{~g})$ was added as a phagostimulant. The experimental diet was the standard diet to which crystalline strychnine was added to obtain a concentration of $0.2 \mathrm{mM}$. Preliminary tests showed that 
this concentration allowed sufficiently high survival $(78 \%$ for $H$. armigera and $75 \%$ for $H$. assulta). The chemicals were added to the diet just after heating the agar, and the mixture was stirred vigorously for about 2-3 $\min [21]$.

\subsection{Chemicals}

Strychnine-HCl was obtained from Sigma-Aldrich (Shanghai, China). Purity of the strychnine was $>97 \%$. For behavioral assays, strychnine was diluted in distilled water. For electrophysiological tests, strychnine was diluted in $2 \mathrm{mM} \mathrm{KCl}$, that served as control solution.

\subsection{Experimental Design and Behavioral Bioassays}

Larvae subjected to behavioral bioassays and electrophysiological tests were reared on standard artificial diet or diet containing strychnine for 5 dietary exposure periods (Figure 1): (a) From neonate to the molt from 4th to 5th instar; (b) $24 \mathrm{~h}$ after the molt to the 5 th instar; (c) $36 \mathrm{~h}$ after the molt to the 5 th instar; (d) $48 \mathrm{~h}$ after the molt to the 5 th instar; (e) $72 \mathrm{~h}$ after the molt to the 4 th instar. In order to be able to study the effects of $72 \mathrm{~h}$ exposure, we used 4th instars for group (e) because 5th instars would have pupated after $72 \mathrm{~h}$. When the results of the tests showed that the caterpillars acquired habituation at a certain time point, we did not test longer exposure times, as we assumed that habituation persisted. Caterpillars for behavioral assays in group (a) were taken at the end of the 4 th instar in the non-feeding pre-molt stage and were deprived of food for about 6-8 h after molting to the 5th instar and then tested [29]. Caterpillars of groups (b), (c), (d), and (e) were deprived of food for about $6-8 \mathrm{~h}$ after they reached the time points indicated.

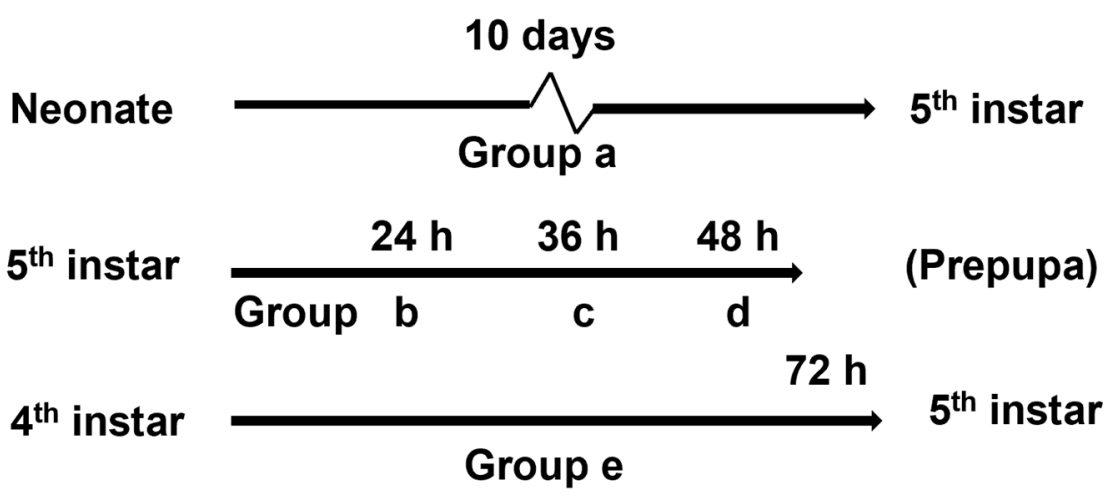

Figure 1. The five exposure protocols to assess habituation of $H$. armigera and H. assulta upon exposure to the deterrent alkaloid strychnine tested in this study.

Caterpillars of group (a) were tested to ascertain whether H. armigera and $H$. assulta exhibited habituation after long term exposure to strychnine. Caterpillar groups (b)-(e) served to investigate how fast $H$. armigera and $H$. assulta habituated when exposed to the deterrent in either the 5th (groups b, c, and d) or 4th instar (group e). Pepper fruit disks were used as the substrate in dual-choice disk tests. Pepper (Capsicum frutescens L. (Solanaceae), cultivar 'JingTian-5') was grown in the greenhouse of Daxing Agricultural Station in Beijing. For each bioassay, 20 replications were performed. Strychnine-HCl was diluted in distilled water immediately prior to application. Five microliters of solution of the test compounds was applied on a disk cut from pepper fruit (thickness $1 \mathrm{~mm}$, surface area $78.5 \mathrm{~mm}^{2}$ ). Taking the disk fresh weight into account, the final concentration of strychnine tested was $2 \mathrm{mM}$, assuming homogeneous distribution through the disk volume. Advantages of pepper fruit disks are that the solutions are absorbed evenly by the fruit tissue and do not leach out. The experiments were carried out in a climatic chamber at a temperature of $25 \pm 1^{\circ} \mathrm{C}$. Larvae were placed individually in the middle of Petri dishes lined with moist filter paper. Four treated and four control disks were alternately arranged in an $\mathrm{ABABABAB}$ fashion around the circumference of the Petri 
dishes. This arrangement was modified relative to earlier studies to ensure that larvae had an equal chance of encountering both treated and control disks [29,30]. Consumption was observed at $1-\mathrm{h}$ intervals thereafter. When ca. $50 \%$ of the control disks or treated disks had been eaten, the disk remains were digitally scanned using a Hewlett-Packard flatbed scanner. Disk surface area was measured using Scion Image (Scion Co., Frederick, MD, USA) (freeware, https: / /ittechgyan.com/download-scion-image-software/, accessed on 14 December 2021). The areas consumed were calculated by subtracting the remaining areas of leaf disks from the average area of 3 reference disks which served as shrinkage controls [31].

\subsection{Electrophysiology}

For each species and every duration of dietary exposure ((a)-(e)), there were two groups of larvae to be tested: caterpillars reared on standard artificial diet and those reared on the diet containing strychnine. The concentrations of strychnine tested were $0,0.01,0.1$, 1, $10 \mathrm{mM}$. The tip recording technique [32] was used to record responses to the different stimuli from the sensilla styloconica on the maxillary galea. Fifth instar caterpillars were used for electrophysiological tests and were starved for $2 \mathrm{~h}$ before testing [33]. Group (e) H. armigera caterpillars were subjected to recording just after they had molted to the 5th instar. Excised caterpillar heads were mounted on a silver wire electrode which was connected to the input of a pre-amplifier (Syntech Taste Probe DTP-1, Hilversum, The Netherlands). Stimulus solutions were filled into glass micropipettes with a tip diameter of c. $30 \mu \mathrm{m}$. Amplified signals were digitized by an A/D-interface (Syntech IDAC-4, Hilversum, The Netherlands) and sampled into an Intel Pentium-based personal computer. Electrophysiological responses were quantified by counting the number of spikes in the first $1010 \mathrm{~ms}$ after the start of stimulation that typically lasted 3-4 s; the first $10 \mathrm{~ms}$ contained the contact artifact and was skipped for analysis. Spikes were counted visually by the experimenter with the aid of Autospike version 3.7 software (Syntech, Hilversum, The Netherlands).

\subsection{Statistical Analysis}

A feeding deterrent index $(\mathrm{FDI})=100(\mathrm{C}-\mathrm{T}) /(\mathrm{C}+\mathrm{T})$ was calculated to quantify strength of deterrence, where $C$ represents the fruit disk area consumed from control disks, $T$ represents the fruit disk area consumed from treated disks. Paired $t$-tests were performed to analyze the disk consumption data. In electrophysiological tests, standard diet-reared caterpillars and deterrent-exposed caterpillars are independent samples; thus, a two sample $t$-test was performed to compare electrophysiological responsiveness of insects reared on different diets. All statistical analyses were conducted using SPSS 13.0 (SPSS Inc., Chicago, IL, USA). $p$ values $<0.05$ were considered significant.

\section{Results}

\subsection{Behavioral Bioassays}

Helicoverpa armigera and $H$. assulta larvae exposed to the standard diet from neonate until the molt to the 5 th instar (group a) were strongly deterred by strychnine (FDI $=40.5$ and 50, respectively; $p<0.01$; Figure 2A). However, H. armigera and H. assulta caterpillars exposed to diet containing strychnine from neonate until the molt to the 5 th instar did not discriminate between pepper disks with strychnine and control disks (FDI = 4.7 and 7.1, respectively; $p>0.05$; Figure $2 \mathrm{~A}$ ).

Helicoverpa armigera 5 th instar caterpillars exposed to standard artificial diet that were raised in parallel to the strychnine-exposed groups (b)-(e), were sensitive to strychnine $(\mathrm{FDI}=46.3,41.5,45.2$, and 42.3, respectively; $p<0.01$; Figure 2B-E). Similarly, $H$. armigera caterpillars which had been feeding for $24 \mathrm{~h}, 36 \mathrm{~h}$, and $48 \mathrm{~h}$ during the 5 th instar on diet containing strychnine were also sensitive to strychnine (FDI $=43.4,39.4$, and 30.5 , respectively; $p<0.01, p<0.01$, and $p<0.05$, respectively; Figure $2 \mathrm{~B}-\mathrm{D})$. However, $H$. armigera 4 th instar caterpillars that had experienced diet containing strychnine for $72 \mathrm{~h}$ 
did not distinguish the pepper disks treated with strychnine from the control (FDI $=10.6$; $p>0.05$; Figure 2E).

Caterpillars of $H$. assulta that had experienced standard artificial diet for $24 \mathrm{~h}, 36 \mathrm{~h}$ and $48 \mathrm{~h}$ since the molt to the 5 th instar (groups (b)-(d)) were highly sensitive to strychnine (FDI $=51,49.6$, and 49.2, respectively; $p<0.01$; Figure 2B-D). Likewise, $H$. assulta caterpillars that had experienced diet containing strychnine for $24 \mathrm{~h}$ and $36 \mathrm{~h}$ were also sensitive to strychnine (FDI $=32.8$ and 26.4, respectively; $p<0.05$; Figure 2B,C). However, $H$. assulta caterpillars that had been feeding on diet containing strychnine for $48 \mathrm{~h}$ did not discriminate the disks treated with strychnine from related control disks (FDI $=12.5, p>0.05$; Figure 2D).
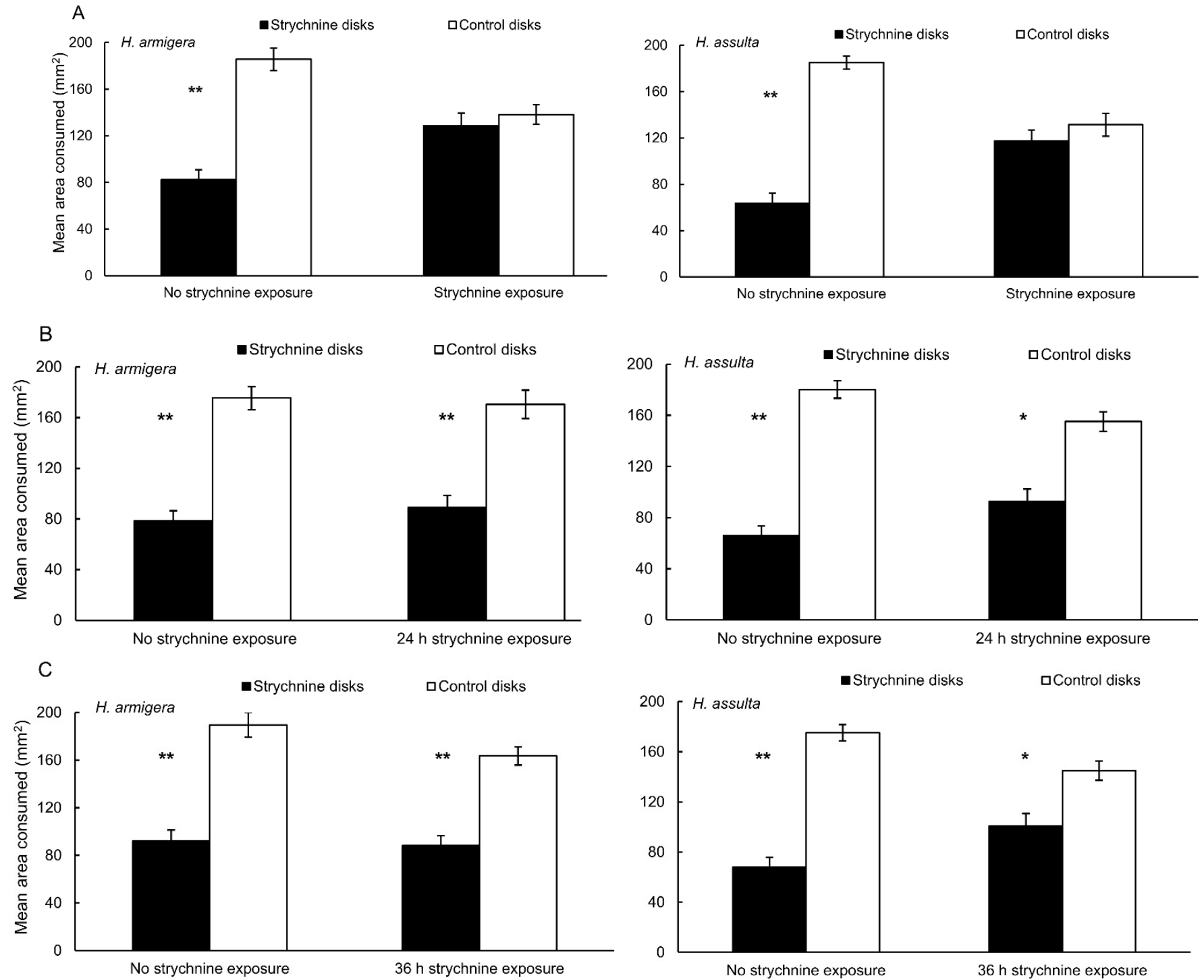

Figure 1. Cont. 

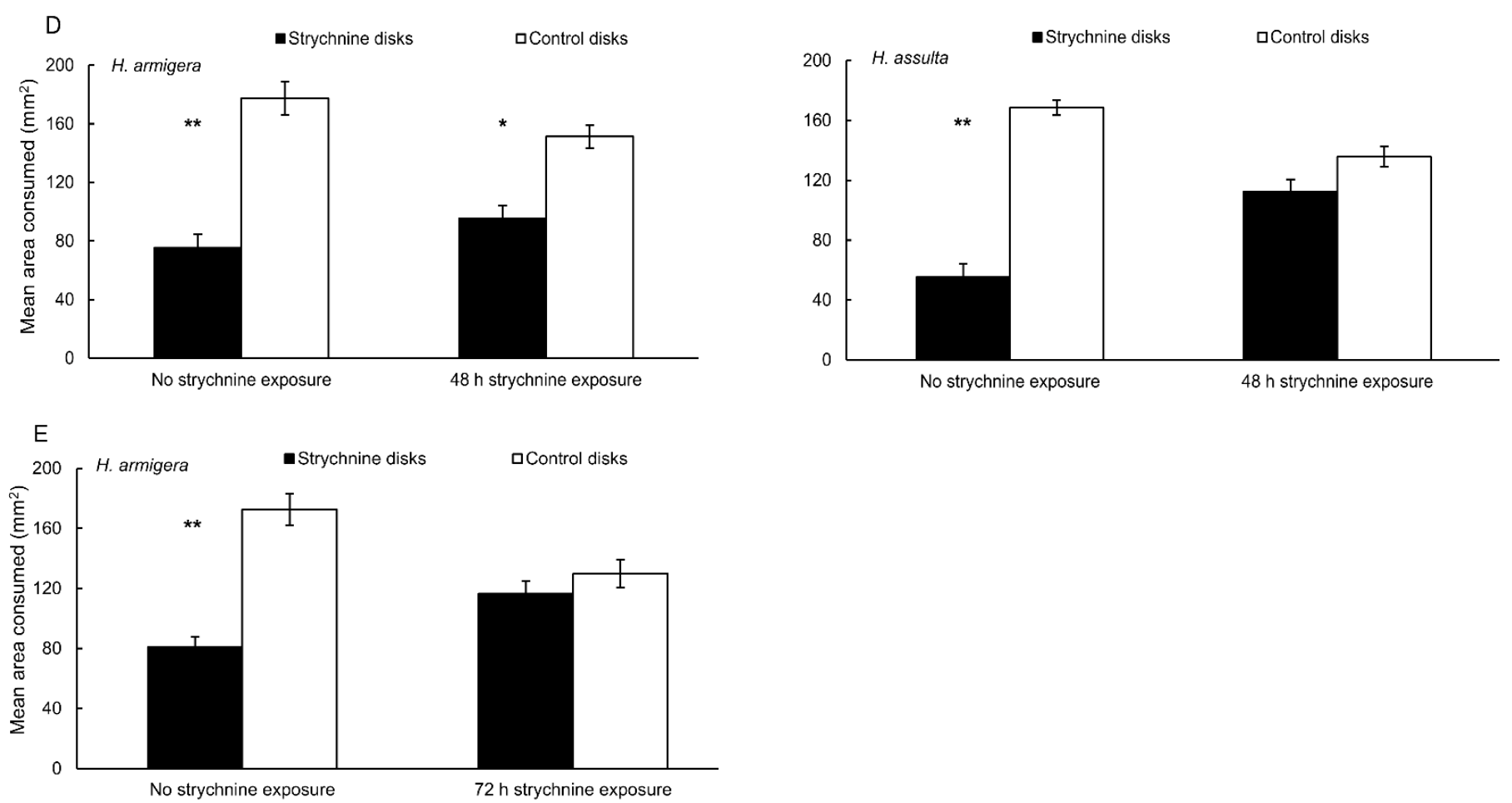

Figure 2. Feeding preference behavior of H. armigera larvae and H. assulta larvae, reared on standard artificial diet (no strychnine exposure) or artificial diet containing strychnine for different durations of dietary exposure, indicated along horizontal axis, on pepper fruit disks in choice assays between control disks and disks containing strychnine. Left lane: $H$. armigera larvae; right lane: $H$. assulta larvae. (A) Exposed from neonate until the molt to the 5th instar; (B) exposed during $24 \mathrm{~h}$ since the molt to the 5th instar; (C) exposed during $36 \mathrm{~h}$ since the molt to the 5 th instar; (D) exposed during $48 \mathrm{~h}$ since the molt to the 5 th instar; (E) H. armigera larvae, exposed during $72 \mathrm{~h}$ since the molt to the 4 th instar; replicated 20 times for each assay. Vertical lines represent standard errors. Asterisks indicate significant differences between treated and control disks according to the paired-samples $t$-test $\left({ }^{*} p<0.05,{ }^{* *} p<0.01\right)$.

\subsection{Electrophysiological Responses}

No electrophysiological response was recorded from the lateral sensilla styloconica of $H$. assulta when stimulated with strychnine in the dose-range tested; strychnine elicited a weak response from the lateral sensilla styloconica of H. armigera [11]. Strychnine elicited a strong response from the medial sensilla styloconica of both $H$. armigera and $H$. assulta caterpillars (Figures 3A and 4B,D). The deterrent neuron in the medial sensilla styloconica of both $H$. armigera and $H$. assulta caterpillars which had been feeding on standard artificial diet was significantly more sensitive to strychnine than the equivalent neuron of caterpillars exposed to diet containing strychnine at $0.1,1$ and $10 \mathrm{mM}(H$. armigera: $p<0.05$, Figure $3 \mathrm{~A}$; H. assulta: $p<0.05, p<0.01$, and $p<0.01$, respectively, Figure $3 \mathrm{~A}$ ). No significant difference was found between the sensitivity of the deterrent neuron in the medial sensilla styloconica of $H$. armigera caterpillars fed on standard artificial diet and those fed on strychninecontaining diet for $24 \mathrm{~h}, 36 \mathrm{~h}$, and $48 \mathrm{~h}$ into the 5 th instar $(p>0.05$, Figure 3B-D). However, when $H$. armigera 5 th instar caterpillars had been exposed to strychnine-containing diet for $72 \mathrm{~h}$, i.e., the entire duration of the 4 th instar, they produced a significantly weaker response to 1 and $10 \mathrm{mM}$ strychnine in the medial deterrent neuron than caterpillars fed on standard artificial diet during the same period ( $p<0.05$; Figure 3E). Similarly, only $H$. assulta caterpillars that had experienced strychnine-containing diet for $48 \mathrm{~h}$ produced a significantly weaker response to 1 and $10 \mathrm{mM}$ strychnine in medial sensilla styloconica than caterpillars that had been feeding on standard artificial diet during the same period $(p<0.05$; Figure 3D). 

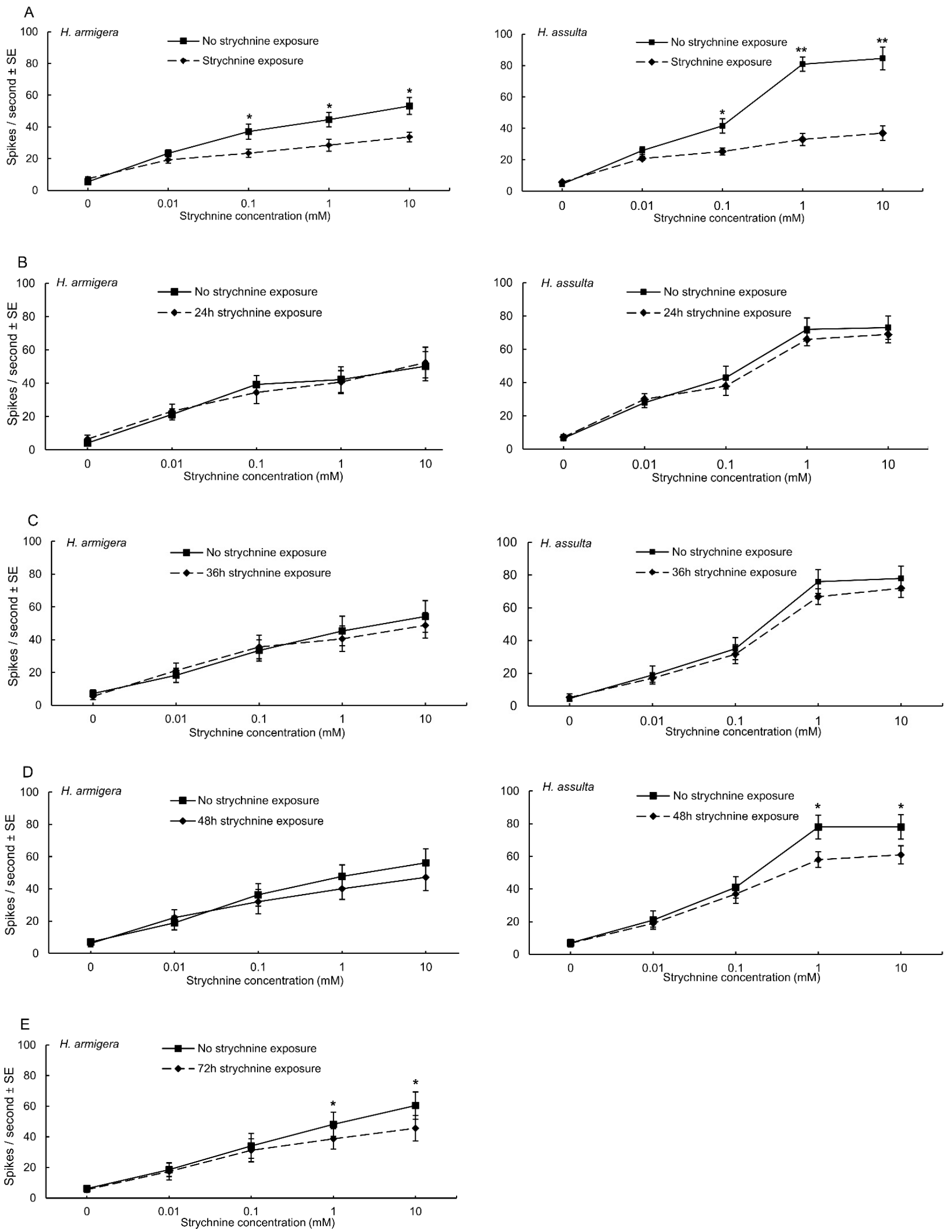

Figure 3. Electrophysiological dose-response curves for strychnine; spike frequencies of the deterrent 
neuron in the medial styloconic sensilla of $H$. armigera and $H$. assulta caterpillars reared either on standard artificial diet (squares, no strychnine exposure) or artificial diet containing strychnine (diamonds) for the intervals indicated. (A) Exposed from neonate until the molt to the 5th instar H. armigera larvae $(n=10)$ and $H$. assulta larvae $(n=11) ;(B)$ exposed during $24 \mathrm{~h}$ since the molt to the 5 th instar; H. armigera larvae $(n=11)$ and $H$. assulta larvae $(n=9) ;(C)$ exposed during $36 \mathrm{~h}$ since the molt to the 5th instar; H. armigera larvae $(n=10)$ and H. assulta larvae $(n=10)$; (D) exposed during $48 \mathrm{~h}$ since the molt to the 5th instar; H. armigera larvae $(n=10)$ and $H$. assulta larvae $(n=10)$. (E) H. armigera larvae, exposed during $72 \mathrm{~h}$ since the molt to the 4 th instar; $n=10$. Vertical lines represent standard errors. Asterisks indicate a significant difference in response frequency between different groups of diet-experienced caterpillars (two-sample $t$-test, ${ }^{*} p<0.05$; ${ }^{* *} p<0.01$ ).
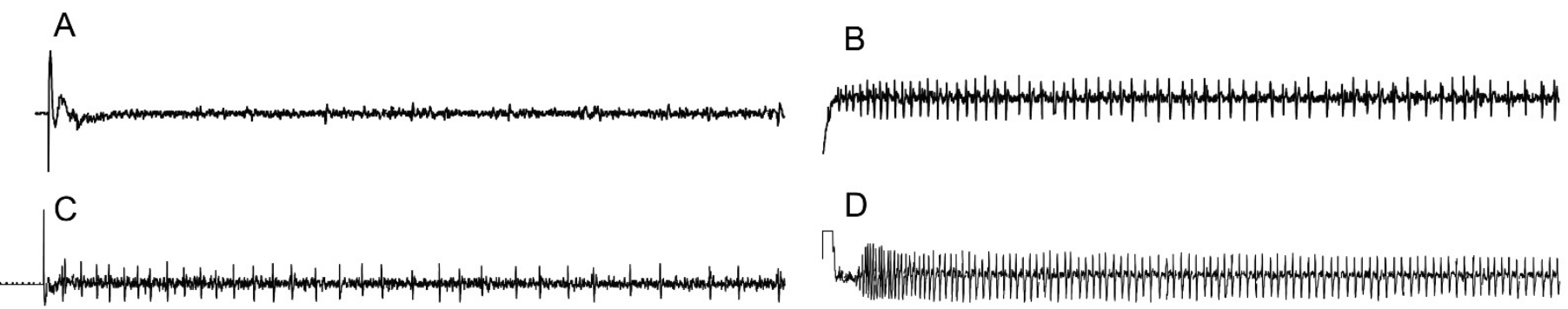

E
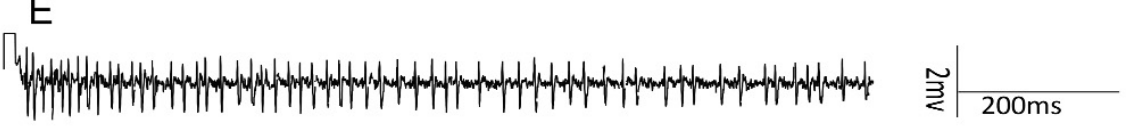

Figure 4. Exemplary recordings of electrophysiological activity in medial sensilla styloconica on the maxillary galea of 5th instar H. armigera and H. assulta caterpillars reared on standard artificial diet or on artificial diet containing strychnine: (A) control ( $\mathrm{KCl} 2 \mathrm{mM})$; (B) strychnine $1 \mathrm{mM}$ on $H$. armigera caterpillars reared on standard artificial diet; (C) strychnine $1 \mathrm{mM}$ on $H$. armigera caterpillars exposed to strychnine-containing diet for $72 \mathrm{~h}$; (D) strychnine $1 \mathrm{mM}$ on $\mathrm{H}$. assulta caterpillars reared on standard artificial; (E) strychnine $1 \mathrm{mM}$ on $H$. assulta caterpillars reared on artificial diet containing strychnine for $48 \mathrm{~h}$. The onset of the stimulations occurred at the start of each trace.

\subsection{Relationship between Electrophysiological and Behavioral Responses}

To examine the relationship between electrophysiological and behavioral responses, these have been plotted against each other (Figure 5). As the duration of exposure increases, both the electrophysiological and behavioral responsiveness diminish, seen as shifts to lower values along the horizontal and vertical axes of the plot in both species. The difference between the two species is that the shift to habituation (values of FDI not significantly different from zero) occurs between 36 and 48 h of exposure in H. assulta (Figure 5B), whereas it occurs between 48 and $72 \mathrm{~h}$ in H. armigera (Figure 5A). 


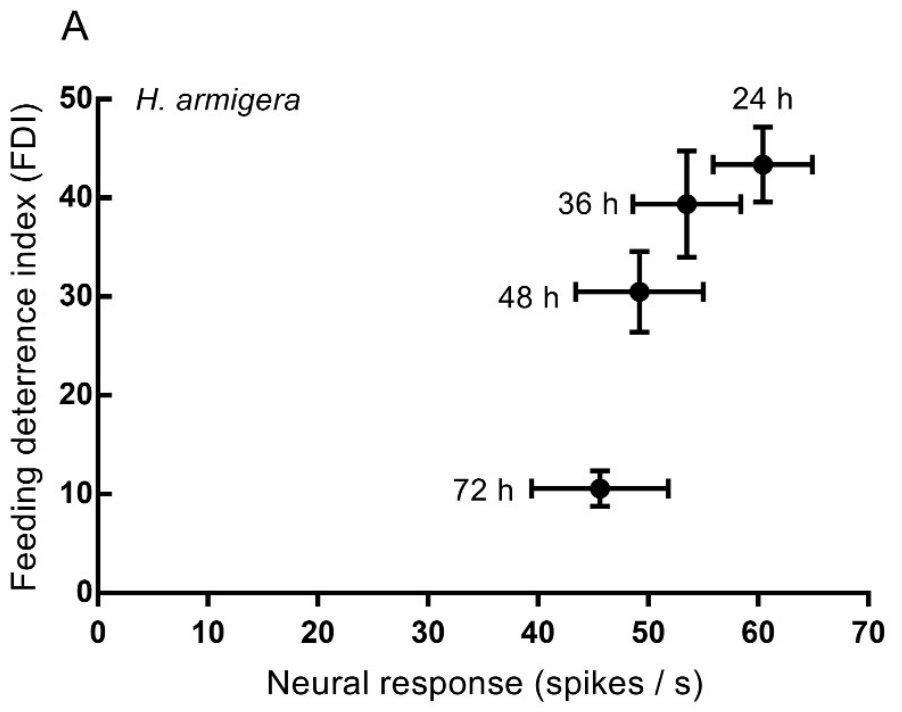

\section{$\mathrm{B}$}

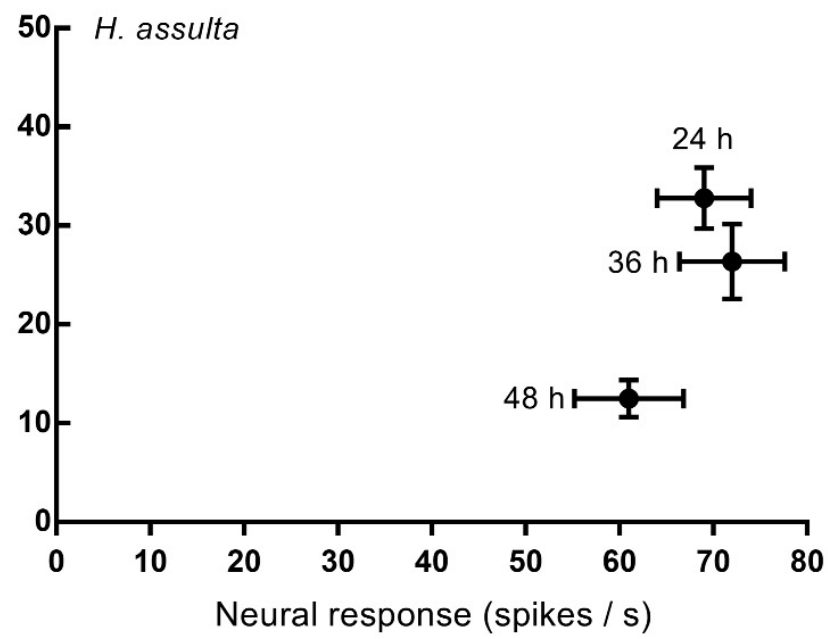

Figure 5. Relationship between electrophysiological and behavioral responses in $H$. armigera and H. assulta caterpillars. Plot of feeding deterrent index (FDI) as a function of electrophysiological response strength upon stimulation with a $10 \mathrm{mM}$ solution of strychnine in (A) H. armigera, (B) H. assulta caterpillars exposed for the durations indicated ( $24 \mathrm{~h}, 36 \mathrm{~h}, 48 \mathrm{~h}$, or $72 \mathrm{~h}$ ). Control solution was $2 \mathrm{mM} \mathrm{KCl}$. Errors bars represent s.e.m.

\section{Discussion}

Dual-or multiple-choice tests have commonly been performed to assess behavioral discrimination between plants [16]. In this study, we used a dual-choice test to evaluate the deterrent effect of strychnine. We selected pepper fruit tissue as the test substrate in behavioral assays because pepper is an acceptable plant for both species, and the solution of strychnine was readily taken up by the fruit disks.

Habituation to deterrent chemicals has been demonstrated in many cases in the laboratory. For example, recent research reported larvae of the generalist herbivore Agrotis ipsilon (Hufnagel) (Lepidoptera: Noctuidae) acquired habituation when they were exposed to the three chemically diverse deterrents strychnine, chlorogenic acid, and fumaropimaric acid [12]. Previous studies also showed that P. rapae caterpillars fed on cabbage (Brassica oleracea L.; one of its favorite host plants) refused to feed on nasturtium (Tropaeolum majus L.; an acceptable but less preferred host plant), and this rejection behavior was ascribed to the presence of the deterrent phenolic chlorogenic acid. However, P. rapae caterpillars reared on nasturtium from neonate onward were desensitized to chlorogenic acid $[8,34]$. When $P$. rapae was reared on artificial diet for its entire larval development, its behavioral discrimination of the chemically diverse deterrents chlorogenic acid, naringin and strychnine was significantly reduced [10]. Dietary experience influenced food selection behavior of other plant-feeding insect species [3,7,9,35-38]. Our previous experiments showed that $H$. armigera caterpillars habituated to strychnine, either when presented on cotton leaf disks or on pepper fruit disks, after feeding from neonate to the 5th instar on an artificial diet containing strychnine [11]. Strychnine is an alkaloid found in the seeds of the Strychnos nux-vomica L. tree, which was proved in previous studies to be a deterrent for several insects among which gypsy moth larvae (Lymantria dispar L.) that has a taste neuron in its medial maxillary styloconic sensillum that responds robustly to this alkaloid [39]. Strychnine activates a bitter-sensitive neuron in I-type sensilla in Drosophila melanogaster (Meigen) (Diptera: Drosophilidae) [40]. Strychnine is not found in the recorded host plants of H. armigera and H. assulta and turned out to represent a strong deterrent for caterpillars reared on the standard artificial diet in the present study (Figure 2A).

Group (a) caterpillars of both species habituated to strychnine after exposure from neonate to the molt to the 5th instar (Figure 2A). Group (b)-(d) H. armigera caterpillars that had experienced strychnine for $24 \mathrm{~h}, 36 \mathrm{~h}, 48 \mathrm{~h}$ since the molt to the 5 th instar preferred 
to feed from control disks over disks treated with strychnine; however, after H. armigera 4 th instar caterpillars fed on diet containing strychnine for $72 \mathrm{~h}$, habituation to strychnine was found (Figure 2E). This suggests that habituation occurred between $48 \mathrm{~h}$ and $72 \mathrm{~h}$ of exposure. For H. assulta, our data showed that this specialist feeder habituated to strychnine after they experienced strychnine-containing diet for $48 \mathrm{~h}$ into the 5 th instar (Figure 2D). Although we cannot exclude that the rate at which habituation develops differs between the 4 th and 5 th instar, we conclude that the specialist $H$. assulta habituated to strychnine faster than the generalist $H$. armigera. This finding is unexpected as we hypothesized that the generalist $H$. armigera would habituate faster to secondary plant compounds. This hypothesis was based on studies on two Heliothis species, taxonomically closely related to Helicoverpa, demonstrating that the specialist species had greater sensitivity to deterrents than the generalist $[4,41]$. However, these studies focused on short-term (3 min) behavioral responses of the two Heliothis species. A major difference with our study is the chronic exposure to the deterrent that resulted in habituation. This suggests that the sensitivity level of naïve individuals, which we also found to be higher in the specialist $H$. assulta (Figure 4B,D), does not predict rate of habituation.

It has been documented that insects fed a standard artificial diet containing a low level of a feeding deterrent show desensitization of receptors responding to these compounds [1]. For example, Manduca sexta fed an artificial diet containing salicin, caffeine or aristolochic acid had reduced taste neuron sensitivity to the corresponding chemicals [21]. Maxillary taste neurons of $P$. brassicae caterpillars were less sensitive to chlorogenic acid when reared on an artificial diet than when reared on cabbage [24]. The closely related species $P$. rapae acquired desensitization in an analogous deterrent neuron in medial sensilla styloconica to chlorogenic acid, naringin, and strychnine upon long-term exposure to a similar artificial diet [10]. Our electrophysiological data on H. armigera and H. assulta are in line with the findings on Manduca and Pieris. Electrophysiological tests on caterpillars exposed to strychnine from neonate to 5 th instar showed that the deterrent neuron in medial sensilla styloconica of both species expressed a significantly reduced sensitivity to strychnine. Interestingly, by testing varying exposure times, the electrophysiological desensitization of the deterrent neuron in medial sensilla styloconica of both species showed a remarkable coincidence in time with the estimated onset of habituation: for H. armigera, the deterrent neuron became significantly less sensitive to strychnine after the caterpillars experienced strychnine diet for $72 \mathrm{~h}$; and the deterrent neuron in medial sensilla styloconica of $H$. assulta also had significantly reduced sensitivity to strychnine after they fed on strychnine diet for $48 \mathrm{~h}$. The sensitivity of taste neurons is not fixed and can change in response to dietary history, suggesting that taste cells possess a "peripheral memory" [1]. In Drosophila, sensory neurons play a very important role in state-dependent gain control of behavior [42]. A recent study showed that $H$. armigera and $H$. assulta adapted to toxic secondary metabolites at gustatory levels, which suggests the taste neurons play an important role in adaptation [43]. Our electrophysiological tests showed that the diet-induced habituation to deterrents can at least partly be explained by chemosensory desensitization of the deterrent neuron. Our results do not exclude that changes have occurred simultaneously in the central nervous system. It has been suggested that the central nervous system plays a part in habituation [18,44]. However, the coincidence between chemosensory desensitization and habituation in our case suggests that peripheral changes play a prominent role in the causation of behavioral habituation. This is in agreement with findings on the black cutworm, A. ipsilon, showing that the same deterrent taste neuron desensitized through dietary exposure was correlated with cross-habituation to two structurally different chemicals [12]. The taste system could contribute to behavioral plasticity by amplifying or attenuating taste input at the level of the central nervous system or directly at the level of the gustatory receptor neurons, which could modulate the level of expression of their different receptor proteins $[45,46]$. We hypothesize taste neuron desensitization may be ascribed to down-regulation of expression of gustatory receptor (GR)-proteins tuned to strychnine and/or to down-regulation of intra- 
cellular signal-transduction cascades. Additional experiments employing gene expression analysis are required to test these hypotheses.

Although our results showed the specialist $H$. assulta habituated to the alkaloid deterrent faster than the generalist $H$. armigera and the desensitization of the deterrent neuron in medial sensilla styloconica offers a physiological explanation for the habituation process, there are a number of limitations to our study that should be noted. First, we only used one deterrent for this comparative study. However, studies showed that when insects habituated to one deterrent, "generalization" $[47,48]$ or "cross-habituation" $[8,10,12]$ can occur, even to molecules of chemically quite diverse classes, such as phenolics and steroids. Second, we confined the electrophysiological tests to the maxillary sensilla styloconica, and, although these play a decisive role in food selection behavior, caterpillars possess additional gustatory sensilla which could mediate detection of deterrents, such as epipharyngeal sensilla [1] and sensilla on the maxillary palp tip [49]. Third, in this study, we focused on the peripheral neural system. However, habituation resulting from dietary history is most likely based on the combined influence of physiological changes in central nervous pathways and peripheral chemosensory desensitization.

The behavioral and electrophysiological results taken together, we conclude that (1) the specialist $H$. assulta habituated to the deterrent strychnine faster than the generalist H. armigera; (2) desensitization of the deterrent neuron in medial sensilla styloconica of both species contributes to the habituation observed; and (3) the coincidence between the behavioral habituation and chemosensory desensitization in both species suggests that peripheral changes play a significant role in the causation of habituation.

Author Contributions: Conceptualization, supervision, project administration, funding acquisition, resources, visualization, writing-review and editing, C.-Z.W. and J.J.A.v.L.; methodology, software, validation, formal analysis, investigation, data curation, writing-original draft preparation, D.-S.Z. All authors have read and agreed to the published version of the manuscript.

Funding: This research was funded by the National Natural Science Foundation of China (Grant Number 31830088 to C.-Z.W.; Grant Number 31201750 to D.-S.Z.), the Royal Dutch Academy of Arts and Sciences (KNAW; Grant Number 05PhD04 to D.-S.Z.) and Scientific Research Fund of Hunan Provincial Education Department (Grant Number 19C0294 to D.-S.Z.).

Institutional Review Board Statement: Not applicable.

Informed Consent Statement: Not applicable.

Data Availability Statement: The data presented in this study are available on request from the first author.

Acknowledgments: We thank Yun-Hua Yan and Ling-Qiao Huang for assistance with insect rearing.

Conflicts of Interest: The authors declare no conflict of interest. The funder had no role in the design of the study; in the collection, analyses, or interpretation of data; in the writing of the manuscript, or in the decision to publish the results.

\section{References}

1. Schoonhoven, L.M.; van Loon, J.J.A. An inventory of taste in caterpillars: Each species its own key. Acta. Zool. Acad. Sci. Hung. 2002, 48, 215-263.

2. Zacharuk, R.Y.; Shields, V.D.C. Sensilla of immature insects. Annu. Rev. Entomol. 1991, 36, 331-354. [CrossRef]

3. Bernays, E.A.; Chapman, R.F. The evolution of deterrent responses in plant-feeding insects. In Perspectives in Chemoreception and Behavior; Chapman, R.F., Bernays, E.A., Stoffolano, J.G., Jr., Eds.; Springer: New York, NY, USA, 1987; pp. $159-173$.

4. Bernays, E.A.; Oppenheim, S.; Chapman, R.F.; Kwon, H.; Gould, F. Taste sensitivity of insect herbivores to deterrents is greater in specialists than in generalists: A behavioral test of the hypothesis with two closely related caterpillars. J. Chem. Ecol. 2000, 26, 547-563. [CrossRef]

5. Chapman, R.F.; Bernays, E.A. Insect behavior at the leaf surface and learning as aspects of host plant selection. Cell. Mol. Life Sci. 1989, 45, 215-222. [CrossRef]

6. Dethier, V.G. The role of taste in food intake: A comparative view. In Mechanisms of Taste Transduction; Simon, S.A., Roper, S.D., Eds.; CRC: Boca Raton, FL, USA, 1993; pp. 3-25.

7. Bernays, E.A.; Singer, M.S. Taste alteration and endoparasites. Nature 2005, 436, 476. [CrossRef] [PubMed] 
8. Huang, X.P.; Renwick, J.A.A. Cross habituation to feeding deterrents and acceptance of a marginal host-plant by Pieris rapae larvae. Entomol. Exp. Appl. 1995, 76, 295-302. [CrossRef]

9. Renwick, J.A.A.; Lopez, K. Experience-based food consumption by larvae of Pieris rapae: Addiction to glucosinolates? Entomol. Exp. Appl. 1999, 91, 51-58. [CrossRef]

10. Zhou, D.S.; Wang, C.Z.; van Loon, J.J.A. Chemosensory basis of behavioural plasticity in response to deterrent plant chemicals in the larva of the small cabbage white butterfly Pieris rapae. J. Insect. Physiol. 2009, 55, 788-792. [CrossRef] [PubMed]

11. Zhou, D.S.; van Loon, J.J.A.; Wang, C.Z. Experience-based behavioral and chemosensory changes in the generalist insect herbivore Helicoverpa armigera exposed to two deterrent plant chemicals. J. Comp. Physiol. A. 2010, 196, 791-799. [CrossRef] [PubMed]

12. Zhou, D.S.; Teng, T.; Liu, J.H.; Long, J.M. Cross-habituation to deterrents correlates with desensitisation of the corresponding deterrent neuron in the larva of the black cutworm, Agrotis ipsilon. Entomol. Exp. Appl. 2021, 169, 1039-1048. [CrossRef]

13. Akhtar, Y.; Rankin, C.H.; Isman, M.B. Decreased response to feeding deterrents following prolonged exposure in the larvae of a generalist herbivore, Trichoplusia ni (Lepidoptera: Noctuidae). J. Insect. Behav. 2003, 16, 811-831. [CrossRef]

14. Del Campo, M.L.; Miles, C.I.; Schroeder, F.C.; Müller, C.; Booker, R.; Renwick, J.A.A. Host recognition by the tobacco hornworm is mediated by a host plant compound. Nature 2001,411, 186-189. [CrossRef]

15. Miles, C.I.; Del Campo, M.L.; Renwick, J.A.A. Behavioral and chemosensory responses to a host recognition cue by larvae of Pieris rapae. J. Comp. Physiol. A. 2005, 191, 147-155. [CrossRef]

16. van Loon, J.J.A.; Tang, Q.B.; Wang, H.L.; Wang, C.Z.; Zhou, D.S.; Smid, H.M. Tasting in plant-feeding insects: From single compounds to complex natural stimuli. In Insect Taste; Newland, P.L., Cobb, M., Marion-Poll, F., Eds.; Taylor and Francis: Abingdon, UK, 2008; pp. 103-126.

17. Sollai, G.; Biolchini, M.; Crnjar, R. Taste receptor plasticity in relation to feeding history in two congeneric species of Papilionidae (Lepidoptera). J. Insect. Physiol. 2018, 107, 41-56. [CrossRef] [PubMed]

18. Del Campo, M.L.; Miles, C.I. Chemosensory tuning to a host recognition cue in the facultative specialist larvae of the moth Manduca sexta. J. Exp. Biol. 2003, 206, 3979-3990. [CrossRef] [PubMed]

19. Glendinning, J.I.; Davis, A.; Ramaswamy, S. Contribution of different taste cells and signaling pathways to the discrimination of "bitter" taste stimuli by an insect. J. Neurosci. 2002, 22, 7281-7287. [CrossRef]

20. Glendinning, J.I.; Domdom, S.; Long, E. Selective adaptation to noxious foods by a herbivorous insect. J. Exp. Biol. 2001, 204, 3355-3367. [CrossRef] [PubMed]

21. Glendinning, J.I.; Ensslen, S.; Eisenberg, M.E.; Weiskopf, P. Diet-induced plasticity in the taste system of an insect: Localization to a single transduction pathway in an identified taste cell. J. Exp. Biol. 1999, 202, 2091-2102. [CrossRef] [PubMed]

22. Glendinning, J.I.; Hills, T.T. Electrophysiological evidence for two transduction pathways within a bitter-sensitive taste receptor. J. Neurophysiol. 1997, 78, 734-745. [CrossRef] [PubMed]

23. Simmons, M.S.J.; Blaney, W.M. Some neurophysiological effects of azadirachtin on lepidopterous larvae and their feeding responses. In Proceedings of the Second International Neem Conference; Schmutterer, H., Ascher, K.R.S., Eds.; G.T.Z: Eschborn, Germany, 1983; pp. 163-180.

24. van Loon, J.J.A. Chemoreception of phenolic acids and flavonoids in larvae of two species of Pieris. J. Comp. Physiol. A 1990, 166, 889-899. [CrossRef]

25. Sollai, G.; Tomassini Barbarossa, I.; Masala, C.; Solari, P.; Crnjar, R. Gustatory sensitivity and food acceptance in two phylogenetically closely related papilionid species: Papilio hospiton and Papilio machaon. PLoS ONE 2014, 9, e100675.

26. Fitt, G.P. The ecology of Heliothis species in relation to agroecosystems. Annu. Rev. Entomol. 1989, 34, 17-52. [CrossRef]

27. Zhao, X.C.; Yan, Y.H.; Wang, C.Z. Behavioral and electrophysiological responses of Helicoverpa assulta, H. armigera (Lepidoptera: Noctuidae), their F1 hybrids and backcross progenies to sex pheromone component blends. J. Comp. Physiol. A 2006, 192, 1037-1047. [CrossRef] [PubMed]

28. Wu, K.J.; Gong, P.Y. A new and practical artificial diet for the cotton bollworm. Entomol. Sin. 1997, 4, 277-282.

29. Tang, Q.B.; Jiang, J.W.; Yan, Y.H.; Van Loon, J.J.A.; Wang, C.Z. Genetic analysis of larval host-plant preference in two sibling species of Helicoverpa. Entomol. Exp. Appl. 2006, 118, 221-228. [CrossRef]

30. Wang, C.Z.; Dong, J.F.; Tang, D.L.; Zhang, J.H.; Li, W.; Qin, J. Host selection of Helicoverpa armigera and H. assulta and its inheritance. Prog. Nat. Sci. 2004, 14, 880-884. [CrossRef]

31. Messchendorp, L.; van Loon, J.J.A.; Gols, G.J.Z. Behavioural and sensory responses to drimane antifeedants in Pieris brassicae larvae. Entomol. Exp. Appl. 1996, 79, 195-202. [CrossRef]

32. Hodgson, E.S.; Lettvin, J.Y.; Roeder, K.D. Physiology of a primary receptor unit. Science 1955, 122, 417-418. [CrossRef] [PubMed]

33. van Loon, J.J.A.; Schoonhoven, L.M. Specialist deterrent chemoreceptors enable Pieris caterpillars to discriminate between chemically different deterrents. Entomol. Exp. Appl. 1999, 91, 29-35. [CrossRef]

34. Renwick, J.A.A.; Huang, X.P. Rejection of host-plant by larvae of cabbage butterfly: Diet-dependent sensitivity to an antifeedant. J. Chem. Ecol. 1995, 21, 465-475. [CrossRef] [PubMed]

35. Glendinning, J.I.; Brown, H.; Capoor, M.; Davis, A.; Gbedemah, A.; Long, E. A peripheral mechanism for behavioral adaptation to specific "bitter" taste stimuli in an insect. J. Neurosci. 2001, 21, 3688-3696. [CrossRef] [PubMed]

36. Jermy, T.; Hanson, F.E.; Dethier, V.G. Induction of specific food preference in lepidopterous larvae. Entomol. Exp. Appl. 1967, 41, $211-230$. 
37. Schoonhoven, L.M. Loss of host plant specificity by Manduca sexta after rearing on an artificial diet. Entomol. Exp. Appl. 1967, 10, 270-272. [CrossRef]

38. Wang, Y.; Ma, Y.; Zhou, D.S.; Gao, S.X.; Zhao, X.C.; Tang, Q.B.; Wang, C.Z.; van Loon, J.J.A. Higher plasticity in feeding preference of a generalist than a specialist: Experiments with two closely related Helicoverpa species. Sci. Rep. 2017, 7, 17876. [CrossRef] [PubMed]

39. Martin, T.L.; Shields, V.D. An electrophysiological analysis of the effect of phagostimulant mixtures on the responses of a deterrent-sensitive cell of gypsy moth larvae, Lymantria dispar (L.). Arthropod-Plant Int. 2012, 6, 259-267. [CrossRef]

40. Hiroi, M.; Meunier, N.; Marion-Poll, F.; Tanimura, T. Two antagonistic gustatory receptor neurons responding to sweet-salty and bitter taste in Drosophila. J. Neurobiol. 2004, 61, 333-342. [CrossRef]

41. Bernays, E.A.; Chapman, R.F. A neurophysiological study of sensitivity to a feeding deterrent in two sister species of Heliothis with different diet breadths. J. Insect. Physiol. 2000, 46, 905-912. [CrossRef]

42. Inagaki, H.K.; de-Leon, S.B.T.; Wong, A.M.; Jagadish, S.; Ishimoto, H.; Barnea, G.; Kitamoto, T.; Axel, R.; Anderson, D.J. Visualizing neuromodulation in vivo: TANGO-mapping of dopamine signaling reveals appetite control of sugar sensing. Cell 2012, 148 583-595. [CrossRef] [PubMed]

43. Sun, L.L.; Hou, W.H.; Zhang, J.J.; Dang, Y.L.; Yang, Q.Y.; Zhao, X.C.; Ma, Y.; Tang, Q.B. Plant metabolites drive different responses in caterpillars of two closely related Helicoverpa species. Front. Physiol. 2021, 12, 460. [CrossRef]

44. Szentesi, A.; Bernays, E.A. A study of behavioural habituation to a feeding deterrent in nymphs of Schistocerca gregaria. Physiol. Entomol. 1984, 9, 329-340. [CrossRef]

45. French, A.; Ali Agha, M.; Mitra, A.; Yanagawa, A.; Sellier, M.J.; Marion-Poll, F. Drosophila bitter taste (s). Front. Integr. Neurosci. 2015, 9, 58. [CrossRef] [PubMed]

46. Zhang, Y.V.; Raghuwanshi, R.P.; Shen, W.L.; Montell, C. Food experience-induced taste desensitization modulated by the Drosophila TRPL channel. Nature Neurosci. 2013, 16, 1468-1476. [CrossRef] [PubMed]

47. Glendinning, J.I.; Gonzalez, N.A. Gustatory habituation to deterrent allelochemicals in a herbivore-concentration and compound specificity. Anim. Behav. 1995, 50, 915-927. [CrossRef]

48. Akhtar, Y.; Isman, M.B. Generalization of a habituated feeding deterrent response to unrelated antifeedants following prolonged exposure in a generalist herbivore, Trichoplusia ni. J. Chem. Ecol. 2004, 30, 1349-1362. [CrossRef] [PubMed]

49. Glendinning, J.I.; Valcic, S.; Timmermann, B.N. Maxillary palps can mediate taste rejection of plant allelochemicals by caterpillars. J. Comp. Physiol. A 1998, 183, 35-43. [CrossRef] 